\title{
The Impact of Computers on Student and Teacher Commitment to Learning and Teaching
}

\author{
Nurit Zehavi and Sherman Rosenfeld \\ Weizmann Institute of Science, Rehovot, Israel, \\ tel: +97289342321, fax: 972-8-9344115, \\ email:nzehavi@weizmann.weizmann.ac.il
}

\begin{abstract}
During the past 15 years, the slow penetration of computers into schools, as well as their limited impact there, gives credence to the claim that computers have had a modest impact on the average student. We identify four possible sources of this limited impact of computers on school learning: (1) lack of a critical mass of computers, (2) inappropriate goals and expectations, (3) insufficient interaction of computers with the content of school learning, and (4) insufficient professional development and related support. What might be the impact of computers and information technology to learning and teaching if serious efforts were undertaken to offset these four limitations?
\end{abstract}

This question was explored in a junior high school, in which each of the four above factors was taken into account. In particular, we instituted (a) a school-wide science and technology fair, in which computers played an important role, and (b) a schoolwide program of teacher inservice training regarding the educational use of computers. Research methods included observations, interviews and questionnaires.

The data revealed the following sequence of events: (1) Students from many different ability levels actively and successfully used the computers in their "Science and Technology Fair" projects. (2) As a result, the teachers demonstrated an attitude shift away from viewing computers as extracurricular and geared to above-average students to viewing computers as integrated into the school curriculum and geared to a wide range of students. Consequently, (3) the teachers took the risk of bringing their low-ability students (without any computer background) to the computer lab. (4) This exposure and new experience resulted in positive attitudes and behavior by students, and (5) increased the commitment of the teachers and administration to the use of educational technology in the school.

This pattern of findings indicates that under the proper conditions, computers can have positive impacts on students and teachers in schools, particularly in their commitment to learning and teaching. Specifically, under the proper conditions, students can act as 
significant catalysts to teachers' learning and adoption of computers and information technology.

\section{Keywords}

Computer integration in schools, professional development, teacher attitudes, commitment, student projects.

\section{INTRODUCTION AND RATIONALE}

Although computers have been increasingly common-place in schools during the last 15 years, there is collective concern that this potential has not been actualized. For example, a national report on the educational impact of technology in American schools (Office of Technology Assessment, 1995) states that today's technologies are essential tools of the teaching trade ... (but) a substantial number of teachers report little or no use of computers for instruction. Similar research findings have been reported elsewhere (Hadley, M. and Sheingold, K. ,1993; Oliver, 1994; Ritchie and Wiburg, 1994). A good case can be made that the impact of computers has generally been on a small group of students ( hackers) and teachers ( enthusiasts) outside the general framework of the formal school classroom.

These reports amount to an urgent wake-up call which poses several critical questions: What factors account for the accepted discrepancy between the promise and practice of information technology in schools? What are possible strategies and practical approaches to decrease this gap? What happens when schools actually adopt these practices? Various approaches to these questions are possible. For example, Hadley and Sheingold (1993) suggest that three factors play key roles in teacher accomplishments: motivation and commitment, support and collegiality, and access to technology.

To investigate these questions, we participated in an effort to integrate computers and information technology (IT) into the daily educational life of an Israeli junior high school.

On a general level, the design of our approach began with identifying and responding to four factors which limit the effective use of computers in schools:

(1) Lack of a critical mass of computers. If computers and information technology are to be effective on a school-wide basis, enough computers need to be available throughout the school. The school was designated as a demonstration project and received a significant number of computers, which were stationed in two computer labs, the library, science labs, and teachers room.

(2) Inappropriate goals and expectations. In the 1980s, when computers were beginning to be used in large numbers in schools, the dominant model was CAI, computer-assisted instruction, in which the goal of computer programs was to teach students directly, with little intervention from the teacher. While CAI approaches are 
still appropriate in some instances, we believe that computers can best be implemented into the curriculum, as tools for learning and teaching, with active participation of the teachers. This perspective informed our approach.

(3) Insufficient interaction of computers with the content of school learning. A major reason to emphasize the computers as tools approach is that it allows teachers and students to experience how they can apply computers to important teaching and learning tasks. As described below, we developed a plan to assist teachers and students to use the computer to help them perform their educational work.

(4) Insufficient professional development and related support. This is perhaps the central problem limiting the effective use of computers in schools. Teachers need significant opportunities for professional development and long-term support. In the context of our study, a long-term inservice was designed to accompany teachers in their progressive integration of computers and information technology in their school.

On a more practical level, we translated the above concerns into a concrete plan of action, which can be summarized as follows:

1. Introduction of the Technology.

2. Setting up an Immediate Catalyst for Student Use of the Computers: The "Science and Technology Fair."

\section{Establishing a Long-Term "In-Class Teacher Inservice."}

\section{Setting up an Extended Catalyst: "The Open Days."}

We believe that this plan should be iterated, i.e., from the extended catalyst (phase 4) to the introduction of advanced technology (new phase 1) to setting up an even more extended catalyst (new phase 2) and so on. In this paper, we describe findings and anecdotes relating to the first iteration of the plan.

\section{THE STUDY AND FINDINGS}

Our study was conducted for the first year following the introduction of the computers to the junior high school. During this time, we followed the changes of the attitudes and behaviors of both the teachers and students through observations, interviews and questionnaires.

Immediately after the computers were installed, we administered a survey of teacher attitudes and plans regarding their future use of technology (Goldberg, Varon, and Zehavi, 1987). At the beginning of the following school year, we administered the same questionnaire to the teachers. Our observation, interview and questionnaire data revealed an interesting pattern of events: 
(1) Enthusiastic Student Use of Technology in the Initial Catalyst Stage: The "Science and Technology Fair." For the previous two years, the science staff of the school had undertaken the organization of a school-wide ' Science and Technology Fair, in which students were invited to choose topics for investigation or invention, conduct research and development projects, and present their work in the form a school-wide exhibition. This year, the school made a commitment to harness this newly-developed school tradition to serve as the context for introducing students to computer-related skills, such as word-processing, graphic design and data analysis. As a result, almost "overnight," the new computers were unpacked, students were given short workshops on related tools (e.g., word processor, graphics programs, spreadsheet) and they were encouraged to use them in their project work.

Students from many different ability levels actively and enthusiastically integrated the technology into the process of working on their science and technology projects; in all, 105 students $(20 \%$ of the school's population) produced 67 projects. These projects included a student video which documented the entire process, as well as an assessment of the Science and Technology Fair from the point of view of the participating students. One of the findings of this assessment was that $76 \%$ of the participating students used computerized tools in the preparation of their projects, i.e., word-processing (40\%), graphic design (15\%), spread-sheet $(15 \%)$, and other tools $(6 \%)$. As one of the senior science teachers remarked:

The Science and Technology Fair this year served as a catalyst to use our computers in the process of learning, in which the students were the pioneers. They learned to use a wide variety of computerized tools in order to work on their projects. It is reasonable to expect that, in the near future, this process will help these students, their friends and the teachers to use computerized tools in the learning process in school.

(2) Resulting attitudinal shift by the teachers. The above forecast was correct. As a result of the students success in using the computers on their science and technology projects, the teachers demonstrated a significant shift in attitudes. They moved away from viewing computers as 'extracurricular and geared to above-average students and began to consider that computers could be integrated into the school curriculum and geared to a wide range of students.

Evidence for this attitudinal shift is demonstrated by the questionnaire we administered before and after the Science and Technology Fair. Before the Fair, about $60 \%$ of the teachers agreed that computers should be used as reinforcement for the good students while only about $40 \%$ agreed that computers should be used as assistance for weak learners. After the Science and Technology Fair, these figures were reversed. About $40 \%$ agreed that computers should be used as reinforcement for the good students while about $60 \%$ agreed that computers should be used as assistance for weak learners.

(3) Resulting behavioral shift by teachers. At the start of the new school year, teachers from all the school disciplines participated in various computer inservices. An intensive in-school inservice in mathematics (Zehavi and Bruckheimer, 1990; Zehavi, 1993) was 
initiated. We observed that teachers gradually took the risk of bringing their lowability students (without any computer background) to the computer lab during the inservice as well as during the regular school program. As the year progressed, more and more teachers did this.

(4) Resulting attitudinal and behavioral shift by students. This increased exposure and experience of students with computers motivated a wide range of students to develop positive attitudes and behavior regarding the computers. In one case, students with learning difficulties were asked to write essays about their experiences in the computer lab. Over $90 \%$ of them wrote that they had fun in working with the computers and that they wanted more; about $50 \%$ related to discipline problems that occurred during the class period and promised to behave better. (It is interesting to note that only about $40 \%$ mentioned the mathematical subject matter.) In another case, the vice-principle was invited to help maintain discipline in the computer lab. He was clearly surprised when the class session was over and the students continued to work at their computers.

(5) Increased commitment of the teachers and administration. As a result of the above, the teachers and administrative staff increased their commitment to the use of educational technology within the school. For example, they are now planning to present several "Open Days" in which a wide range of computer-based projects will be presented by students and teachers to the general community.

\section{DISCUSSION}

We can summarize the findings of our study as follows:

First, it is clear that the professional development of teachers is a key aspect of any effective plan to integrate computers in schools. However, we are aware that teachers can often be reluctant learners. Our study demonstrates that, when given the proper conditions, students can't wait to jump into the action and can serve as a catalyst to teacher involvement.

Second, the study illustrated that the "Science and Technology Fair" provided a very effective context for the development of students' computer skills, because within this context, students had a real need to develop these skills.

Third, we found out that teachers, who see evidence of how students positively respond to computers (as they did during the Fair and the in-class inservice), themselves become more motivated and committed to use computers in their classrooms as well with students from a wide variety of backgrounds. This finding suggests that teachers should work with students as a regular aspect of their professional development programs. Part of this work should help teachers build on student curiosity and motivation, which is generated in the computer lab, in order to deepen student understanding. 
Finally, our study demonstrates that there are significant social impacts associated with the effective use of computers in schools. Specifically, when computers are authentically used to help students and teachers achieve their goals, both groups become more committed to learning and teaching. In this way, all of the "players" within the school framework become committed to educational change. In this regard, we strongly agree with the conclusion of Ritchie and Wiburg (1994):

"Technology's greatest power may be the way in which its use causes teachers, administrators, and students to rethink teaching and learning. A relationship exists between schools with a high degree of technology implementation and those that are rethinking the process of education. In the context of a global information age, where change is inevitable, restructuring education with technology has the potential to become a catalyst to help solve our educational dilemmas.

\section{REFERENCES}

Brown, A. (1994) Processes to support the use of information technology to enhance learning. Computers in Education, 22: 145-153.

Goldberg, D., Varon, Y. and Zehavi, N. (1987) Survey of mathematical software implementation. Technical Report M87/9. Department of Science Teaching, The Weizmann Institute of Science.

Hadley, M. and Sheingold, K. (1993). Commonalities and distinctive patterns in teachers' integration of computers. American Journal of Education, 101, 261315.

Oliver, R. (1994) Factors influencing beginning teachers uptake of computers. Journal of Technology and Teacher Education, 2(1), 71-89.

Ritchie, D. and Wiburg, K. (1994) Educational variables influencing technology integration. Journal of Technology and Teacher Education, 2(2), 143-153.

U.S. Congress, Office of Technology Assessment (1995) Teachers and Technology: making the connection. OTA-EHR-616. Washington, D.C.: Government Printing Office.)

Zehavi, N. (1993) Supporting an active role for the teacher in computer assisted learning. Journal of Technology and Teacher Education, 1 (4), 353-372.

Zehavi, N. and Bruckheimer, M. 1990) An approach to integrating educational software into the curriculum. Journal of Computer-Assisted Learning, 6, 190-201.

\section{BIOGRAPHY}

Nurit Zehavi received her Ph.D. in the Science Teaching Department of the Weizmann Institute of Science. In 1984 she was appointed to coordinate the development, research and evaluation of educational software in mathematics at the Science Teaching Department. In 1990-1992 she served as the Chair of the Israeli Association of Computers in Education. She is involved in activities aimed at advancing the professional development of mathematics teachers who specialize in computer applications. 
Sherman Rosenfeld received his Ph.D. in Science and Math Education from U.C. Berkeley and directed a science museum in California for 3 years. In 1982 he immigrated to Israel and has since conducted research and development on science education projects at the Weizmann Institute of Science. He directed the Department for Science-Oriented Youth in the Israeli Ministry of Education as well as the Agam Project for Visual Education in the Science Teaching Department. He is currently participating in the Department's efforts to develop a national curriculum in science and technology for junior high schools in Israel. 